\title{
PROGRAMA EDUCAÇÃO POPULAR, SAÚDE E CIDADANIA: UM RELATO DE EXPERIÊNCIA SOBRE A EXTENSÃO UNIVERSITÁRIA
}

\author{
Rosineia Novais Oliveira ${ }^{1}$ \\ Ivone Gonçalves Nery ${ }^{2}$ \\ Anne Verenna Gonçalves Nery ${ }^{3}$ \\ Lizandra Almeida Nascimento ${ }^{4}$ \\ Wellington Gonçalves Nery ${ }^{5}$
}

\begin{abstract}
Resumo
O diálogo entre as diferentes instâncias sociais traz contribuições para a produção de material educativo e informacional coerente com a cultura dos movimentos e grupos populacionais, propiciando a eficácia da educação e comunicação. O programa objetivou promover rodas de EPS Educação Popular em Saúde -, por meio de reuniões, oficinas, ações educativas, leitura e reflexões de textos que resultaram em discussão, desconstrução, construção, aproximações e encontros com os sujeitos de diversos segmentos sociais, para promover novos saberes e práticas em saúde através do diálogo, criando vínculos de corresponsabilidade na socialização de experiências e atitudes críticas/reflexivas em ações coletivas, para que a saúde seja, de fato, a conquista da luta popular. O mecanismo é utilizado por meio de rodas de discussões, seminários, oficinas e visitas domiciliares. $\mathrm{O}$ programa fundamentou-se na promoção de rodas de EPS, como estratégias de diálogo que promovam a saúde na perspectiva da participação social, enquanto promotora da cidadania Nesse sentido, trilhar pelos caminhos da EPS requer atos pedagógicos que permitam que as informações sobre as questões de saúde contribuam para dar visibilidade histórica, social e política, assim como o apoderamento de grupos sociais nas suas necessidades e reivindicações, e permita projetar caminhos prazerosos, educativos e inclusivos de aprender a estar com o outro. Pretende-se, neste relato, descrever a experiência vivenciada com a educação popular, compartilhando a trajetória do grupo e as repercussões entre os participantes e comunidade.
\end{abstract}

Palavras-chave: Cidadania. Educação Popular. Saúde.

\begin{abstract}
The dialogue between the different social instances brings contributions to the production of educational and informational material coherent with the culture of the movements and population

\footnotetext{
${ }^{1}$ Acadêmica do Curso de Enfermagem pela Universidade Estadual do Sudoeste da Bahia. Bolsista Voluntário do Programa Educação Popular, Saúde e Cidadania. E-mail: rosineia.novais@ outlook.com.

${ }^{2}$ Enfermeira. Mestre pela Universidade do Rio de Janeiro. Professora assistente do Departamento de Saúde II da Universidade Estadual do Sudoeste da Bahia-UESB campus de Jequié-BA. Coordenadora do Programa Educação Popular Saúde e Cidadania.

${ }^{3}$ Enfermeira. Especialista em Saúde Pública pela Faculdade de Tecnologia e Ciências-FTC, Campus de JequiéBA.

${ }^{4}$ Acadêmica do Curso de Enfermagem pela Universidade Estadual do Sudoeste da Bahia. Bolsista Voluntário do Programa Educação Popular, Saúde e Cidadania.

5 Jornalista. Mestre pela Universidade Estadual do Sudoeste da Bahia. Orientador do Programa Educação Popular, Saúde e Cidadania.
} 
groups, favoring the effectiveness of education and communication. The program aimed to promote the wheels of EPS - Popular Education in Health - through meetings, workshops, educational actions, reading and reflections of texts. Those things resulted in discussion, deconstruction, construction, approximations and encounters with individuals from different social segments to promote new knowledge and practices in health through dialogue, creating bonds of co-responsibility in the socialization of experiences and critical / reflexive attitudes in collective actions, so that health is indeed the conquest of popular struggle. The mechanism is used through discussion wheels, seminars, workshops and home visits. The program was based on the promotion of EPS wheels, as strategies for dialogue that promote health in the perspective of social participation, as a promoter of citizenship. In this sense, to follow the paths of EPS requires pedagogical actions that allow information on health issues that contribute to giving historical, social and political visibility, as well as the empowerment of social groups in their needs and demands, and allows to design pleasant, educational and inclusive ways of learning to be with the other. The purpose of this report is to describe the experience of popular education, sharing the group's trajectory and the repercussions between the participants and the community.

Keywords: Citizenship. Popular Education. Health.

\section{Introdução}

A Educação Popular em Saúde (EPS), como "diretriz teórica e metodológica da política de Educação em Saúde do Ministério da Saúde” (BRASIL, 2007), propõe estratégias que possam ser incorporadas nos cursos de graduação da área de saúde. A Educação Popular em Saúde é um processo que busca estabelecer relações pedagógicas emergentes de cenários e de vivências de aprendizagem, que articulam as subjetividades coletivas e as relações de interação que acontecem nos movimentos sociais, implicando na aproximação entre agentes formais de saúde e população.

Na perspectiva de Brasil (2007), a EPS propicia, ainda, a comunicação dialógica e dialética, assim como permite a socialização de experiências e atitudes reflexivas e críticas, individuais e coletivas, norteadas pelos princípios do saber ouvir, de reconhecer que ninguém está só, de desmontar a visão mágica, de aprender/estar com o outro e de assumir a ingenuidade do educando, além de correr riscos e começar a reaprender de novo, e de viver pacientemente impaciente.

A educação popular em saúde é, segundo Vasconcelos (1997), um modo especial de conduzir o processo educativo, na perspectiva da apuração, organização e aprofundamento do sentir, pensar e agir das diversas categorias de sujeitos e grupos oprimidos da sociedade. Busca trabalhar pedagogicamente o ser humano no processo de participação popular, 
fomentando formas coletivas de aprendizado e investigação, de modo a promover o crescimento da capacidade de análise crítica sobre a realidade para intervir sobre ela.

Desse modo, a educação popular em saúde emerge como ferramenta fundamental nesse processo, para a busca de soluções, por meio de enfrentamentos dos problemas de saúde, seus determinantes e condicionantes, uma vez que, de acordo com Gomes (2011), o contexto atual de fragmentação da vida social requer a recomposição de uma abordagem mais integral e humanizada da saúde.

As experiências de educação popular em saúde têm reafirmado o poder deste dispositivo para a articulação dos níveis de atenção e gestão e na formulação de políticas de saúde com corresponsabilidade e comprometimento com os princípios do SUS. Logo, devem ser valorizadas, qualificadas e adotadas nos processos de educação permanente para o controle social e na mobilização em defesa do SUS, por meio de vivências relevantes para os movimentos sociais, na defesa de uma sociedade justa, equânime e democrática, conforme sugerido por Chaves et al (2014).

O conhecimento, na perspectiva da educação popular, não é de domínio de certo grupo ou classe, e, para ser acessível à população, precisa apenas ter sua transmissão facilitada. $\mathrm{O}$ conhecimento é construído no diálogo entre sujeitos, pois conhecimento, aqui, é consciência da realidade e da condição humana. Nesse sentido, Carvalho, Acioli e Stotz (2001) apontam que "uma postura que propicie o diálogo pressupõe a compreensão de que os saberes da população são elaborados sobre experiência concreta, sobre vivências distintas daquelas do profissional".

Esse projeto justifica-se pela necessidade de estratégias que possibilitem aos partícipes se integrarem à realidade social das áreas em que atuam, de modo que estes encontrem o sentido da vida, reconheçam sua identidade social e incorporem mecanismos de enfrentamento da luta pela sobrevivência, sem perder a noção de direitos e deveres, respeitando a diversidade cultural, proposta apresentada por Morin (2001). Assim, o estudo tem como objetivo descrever as práticas realizadas no programa de extensão e suas contribuições para a promoção da saúde e cidadania.

\section{Metodologia}

Trata-se de um estudo do tipo relato de experiência, baseado na abordagem descritiva praticada por meio da extensão universitária, que foi desenvolvida pela docente e discentes 
dos cursos de Enfermagem e Fisioterapia da Universidade Estadual do Sudoeste da Bahia, durante as ações no "Programa de Extensão Educação Popular, Saúde e Cidadania". O programa aborda a motivação de diversos sujeitos sociais para as questões que envolvem a saúde, a cidadania, a participação e o controle social, como espaço político de problematização das questões sociais, dentre elas, as ações de saúde e educação, desde o ano letivo de 2016 até os dias atuais.

São realizadas reuniões semanais com os membros do programa para discussão de temas pertinentes à população, assim como para elaboração do material a ser utilizado durante a execução das atividades. Dentre as ações educativas promovidas pelo programa, para trazer mais conhecimento aos membros, encontram-se rodas de discussões, seminários, debates e oficinas. Algumas atividades são realizadas com o auxílio de data show e equipamento de áudio, porém, na maioria das vezes, estes equipamentos não são utilizados, por questões relacionadas ao ambiente e viabilidade de instalação. Nesses casos, o programa remaneja sua metodologia para um diálogo pontuado, visando uma abordagem dos principais eixos da discussão. Nas ações, também são distribuídos panfletos e folders com finalidade informativa.

Assim, até então, o programa de extensão usa como recursos didáticos as seguintes ações, nas respectivas etapas: reuniões semanais para leitura, reflexão e discussão de textos; exibição de vídeos como ferramentas para os partícipes construírem e desconstruírem saberes e práticas; roda de conversas; oficinas; círculos de cultura e cenopoesia. Realizamos, ainda, visitas domiciliares, além de visitas às comunidades e instituições, buscando integrar a vivência da Educação Popular em Saúde com a prática, para problematização dos diversos aspectos dos problemas vivenciados no cotidiano das realidades encontradas. O público alvo abrange a comunidade acadêmica e demais segmentos da sociedade.

\section{Resultados e discussão}

Os resultados apontam para a ampliação de práticas como essas, que promovem a integração acadêmica com a sociedade. Destaca-se a participação de membros do programa em eventos como o Fórum de Enfermagem e a Conferência Municipal de Saúde da Mulher. Foram realizadas duas oficinas que versavam sobre Educação em Saúde, durante a II Semana de Saúde do Batalhão da Polícia Militar. Outra oficina foi realizada na $78^{a}$ Semana Brasileira de Enfermagem, em uma universidade pública no interior da Bahia, com orientação da coordenação do programa, juntamente com os bolsistas voluntários e remunerada. 
$\mathrm{Na}$ primeira oficina, foi realizada uma exposição dialogada sobre o livro: "Quem somos nós?" (ROSA, 2005), seguida de discussões e reflexões sobre o tema apresentado, bem como de uma roda de discussão sobre relacionamento interpessoal e sobre como a prática favorece o enfrentamento de situações limites no processo saúde-doença. Foram feitas, ainda, discussões, reflexões e abertura para a tomada de consciência sobre novos processos de aprendizagem. Nessa atividade, obtivemos a participação de todos os policiais.

Já na segunda oficina, foi realizada uma roda de discussão sobre conceitos religiosos, e de como a prática da espiritualidade favorece o enfrentamento no processo saúde-doença. Das discussões e reflexões, surgiram os conceitos de transcendência, significando abertura para a tomada de consciência para novos processos de aprendizagem. e imanência, como o fechamento em si mesmo, rejeitando as possibilidades de novos saberes.

A força da espiritualidade é estabelecida como um instrumento de promoção da saúde que permite superar o limite do conhecimento científico da biomedicina, a qual não consegue responder às múltiplas dimensões do ser humano, como as físicas, as psíquicas, as sociais e as espirituais. Pudemos perceber a disposição do público alvo com relação às atividades desenvolvidas. Em cada oficina realizada, notava-se a grande dedicação e superação da dificuldade deparada.

A saúde, enquanto política social, tem estabelecido princípios e diretrizes que buscam assegurar direitos e promover responsabilização dos gestores, trabalhadores de saúde e da sociedade para sua promoção, em seus diversos contextos. Portanto, atuar na perspectiva da EPS possibilita a apropriação de conhecimentos, práticas e saberes que favoreçam a promoção da saúde enquanto produção social e valorização da cultura e identidade das classes populares, para que educando e educadores se auto eduquem e eduquem aos outros, escutando as necessidades sociais e de saúde que apresentam os diversos grupos sociais.

Destaca-se o incentivo aos discentes das disciplinas Fundamentos do Processo de Cuidar I; Enfermagem em Saúde do Idoso, do curso de Enfermagem, e a disciplina Estágio em Comunidade, do curso de Fisioterapia, em inserir ações educativas nas práticas dessas disciplinas durante a formação acadêmica. Essas práticas propiciam a divulgação de informações à sociedade e oportunizam aos discentes a ampliação de saberes, além de desenvolverem a capacidade de relacionamento entre os diversos meios sociais.

E, como aprendentes do processo, é necessário que todos se sintam sujeitos da ação educativa, o que é fundamental para a realização de ações transformadoras em equipe, com o 
entendimento de que atuar politicamente e de forma correta no que diz respeito à saúde das pessoas requer conhecimentos dos processos que interferem nas questões de saúde.

Com base nisso, realizou-se capacitação em Educação Popular em Saúde para os membros do programa, sendo este um curso de curta duração. Na primeira etapa, realizamos momentos de círculos de cultura, voltados para os diversos temas que envolvem a saúde coletiva. No segundo momento, realizamos roda de conversa sobre educação popular na abordagem da espiritualidade do trabalho em saúde, estudos sobre controle social, participação popular, deficiência física, auditiva e visual. Consideramos que discutir questões que envolvem pessoas com deficiências são mecanismos de contribuição para a promoção da inclusão social destas.

De acordo com a perspectiva de Chaves et al (2014), as práticas educativas, a partir da educação popular em saúde, têm contribuído para o controle social e a participação popular, quando produzem conhecimento na troca de saberes e contribuem na discussão, formulação, produção e apresentação de demandas pelo direito à saúde.

Em nosso projeto, buscamos integrar a vivência da Educação Popular em Saúde com a prática, para problematização dos diversos aspectos dos problemas vivenciados no cotidiano das realidades encontradas, com o intuito de buscar promover uma educação em saúde com qualidade e provocar uma melhora na qualidade de vida dos envolvidos, proporcionando, também, uma troca de saberes.

A organização das atividades permite a realização mais precisa e a capacitação serve como um momento de orientação e amplificação do conhecimento acerca da educação popular em saúde. Cada exposição foi planejada e direcionada de acordo com as necessidades vistas no público-alvo.

Segundo Barros (2007), a necessidade da construção de um novo olhar para o cuidado, baseado no diálogo e na criatividade, possibilita a transformação social do papel dos profissionais no exercício da sua prática. Ouvir reflexivamente é uma das técnicas de comunicação terapêuticas de maior efetividade, o que lhe dá um caráter de instrumento essencial para que o enfermeiro estabeleça o relacionamento terapêutico. Daí a importância da reflexão de que da mesma forma que não se deve ter uma visão reduzida ao corpo biológico, há de se ter uma visão holística do ser biopsicossocial, como afirma Oliveira (2005).

A experiência em fazer parte de um programa de extensão universitária é ter a certeza de que somos capazes e que temos algo a oferecer e compartilhar ao próximo, pois o 
compartilhar de ideias e pensamentos são tão enriquecedores quanto o conhecimento científico. Sem dúvida, a oportunidade de vivenciar a experiência como voluntários de um programa de extensão foi muito gratificante. Levando em conta o interesse pela área da educação popular, temos a convicção de que a participação do programa será de fundamental importância em nossa vida pessoal, acadêmica e profissional, pois, a partir daí, será aberto um caminho de oportunidades em nossa trajetória profissional.

As realizações de palestras educativas são de grande importância, uma vez que este momento serve tanto para exposição quanto para o conhecimento das necessidades de saúde da população, seja no âmbito individual ou coletivo, viabilizando, assim, ações presentes e futuras. Durante as ações do programa, notamos uma boa receptividade do público, que participou dos nossos debates e ajudou a construir o conhecimento, deixando-nos cada vez mais motivados a trabalhar e discutir as temáticas. As temáticas discutidas foram de grande importância para a população, contribuindo para a melhoria na sua qualidade de vida e de esclarecimento ou aprimoramento do conhecimento.

Assim, cumprimos com o que é afirmado por Pelicione (2007), para quem "a promoção da saúde é viabilizada pela educação em saúde, processo político de formação para a cidadania ativa, para a ação transformadora da realidade social e principalmente, na busca da melhoria na qualidade de vida" (PELICIONE, 2007).

A falta de acesso às informações gera uma grande deficiência no conhecimento. Nas atividades realizadas, foi possível constatar que o diálogo é mais proveitoso do que apenas uma simples entrega de panfletos, pois desperta o interesse e induz a participação e o entrosamento do público alvo junto às atividades desenvolvidas. Entende-se a comunicação e educação em saúde como processos sociais que, atualmente, não podem caminhar separados, e devem contribuir para o desenvolvimento da sociedade.

Com isso, cumprimos a sugestão de Freire (2011), que afirma que a prática educativa pautada no diálogo e na troca de saberes valoriza o conhecimento popular, o estímulo e o respeito à autonomia do sujeito no cuidado de sua própria saúde e o incentivo à participação ativa no controle social, com vistas a contribuir na melhoria das condições de vida e saúde da população.

Desse modo, educação popular emerge como ferramenta fundamental nesse processo, para a busca de soluções por meio de enfrentamentos dos problemas de saúde, seus determinantes e condicionantes, uma vez que o contexto atual de fragmentação da vida social 
requer a recomposição de uma abordagem mais integral e humanizada da saúde e esta não pode ficar restrita apenas às iniciativas das instituições e de profissionais de saúde.

\section{Conclusão}

Conclui-se que as ações do programa são essenciais para a melhoria da qualidade de vida, tanto no âmbito individual como coletivo. Não obstante, essas práticas possibilitaram aproximações e encontros com sujeitos de diversos segmentos sociais, promovendo novos saberes e práticas de saúde em uma relação dialógica, que favoreceu vínculos de corresponsabilidade na socialização de experiências e atitudes. Portanto, atividades como essas são imperiosas para o desenvolvimento social, devendo ser norteadas pelos princípios do direito à informação e da participação da comunidade e igualdade.

As ações desenvolvidas durante toda a prática tiveram o objetivo de promover o interesse dos indivíduos envolvidos. Tais atividades exigiram planejamento das ações e iniciativa, por parte da docente e discentes envolvidos no programa, na busca pela criação do vínculo, numa postura ativa, de criatividade e sensibilidade, para entender a linguagem nãoverbal.

As práticas de educação em saúde realizadas no Brasil pelos profissionais de saúde descritos na literatura pesquisada enfocam a participação de todos os envolvidos nas práticas de saúde construtivistas. Isso mostra-se como um método efetivo e traz muitos benefícios significativos, tanto para os indivíduos envolvidos quanto para os profissionais de saúde, principalmente na construção do auto cuidado consciente e do controle de determinada doença, contribuindo para a melhoria da qualidade de vida. Destaca-se, também, o importante papel destes profissionais, integrados a uma equipe interdisciplinar, que tem na educação popular em saúde o eixo norteador da sua assistência.

É importante ressaltar que o profissional de saúde não deve se colocar como o indivíduo detentor do conhecimento e de uma verdade que deve ser apenas prontamente seguida sem reflexão prévia por parte da população. Devemos, antes de iniciar o processo de comunicação, conhecer a medicina popular e seus atores sociais, fazendo com que a prática da educação em saúde seja uma relação de troca entre o saber popular e científico, ambos se enriquecendo reciprocamente, valorizando, assim, a cultura local. 


\section{REFERÊNCIAS}

BARROS, S; OLIVEIRA, M.A.F; SILVA, A.L.A. Práticas inovadoras para o cuidado em saúde. Revista da Escola de Enfermagem da USP [online], v.41 p. 815-9, 2007.

BRASIL. Ministério da Saúde. Secretaria de Gestão Estratégica e Participativa e Departamento de Apoio à Gestão Participativa. Caderno de Educação Popular em SaúdeBrasília, 2007.

CARVALHO, M. A. P.; ACIOLI, S.; STOTZ, E. N. O processo de construção compartilhada do conhecimento. A saúde nas palavras e nos gestos: reflexões da rede de educação popular e saúde. São Paulo: Hucitec, p. 101-14, 2001.

CHAVES, L; ALVES, A.C; SOUZA, J; BARROS, L; ARAUJO, P.D; SILVA, T.P.C. Curso Participação popular, movimentos sociais e direito à saúde: uma experiência de educação popular em Saúde na Bahia a partir do Mobiliza SUS. Interface, Botucatu, v. 18, supl.2, p. 1507-1512, 2014.

FREIRE, P. Pedagogia do oprimido. 50ª ed. Rio de Janeiro: Paz e Terra, 2011.

GOMES, L. B.; MERHY, E. E. Compreendendo a Educação Popular em Saúde: um estudo na literatura brasileira. Cad. Saúde Pública, Rio de Janeiro. Janeiro, 2011.

MORIN, E. Os sete saberes necessários à educação do futuro. 10. Ed. São Paulo: Cortez; Brasília: UNESCO, 2001.

OLIVEIRA, O.S; NÓBREGA, M.M.L; SILVA, A.T; FILHA, M.O.F. Comunicação terapêutica em enfermagem revelada nos depoimentos de pacientes internados em centro de terapia intensiva. Revista Eletrônica de Enfermagem. v. 07, n.1, p.54-63, 2005.

ROSA, M.S.O. Quem somos Nós? Divulgação em saúde para debate, Série Conasems. Rev. Saúde e Paz. Rio de Janeiro, 2005.

VASCONCELOS, Eymard Mourão. Educação popular nos serviços de saúde. 3ed. São Paulo: Hucitec, 1997. 
